\title{
QUALITY PRACTICES: AN OPEN DISTANCE LEARNING PERSPECTIVE
}

\author{
Dr. Kemlall RAMDASS \\ Department of Mechanical and Industrial Engineering \\ University of South Africa \\ Pretoria, South Africa \\ Dr. Fulufhelo NEMAVHOLA \\ Department of Mechanical and Industrial Engineering \\ University of South Africa \\ Pretoria, South Africa
}

\section{ABSTRACT}

Global transformation in higher education over the past two decades has led to the implementation of national policies in order to measure the performance of institutions in South Africa. The Higher Education Quality Council (HEQC) adopted the quality assurance (QA) model for the purposes of accountability and governance in South African Higher Education. The first Council of Higher Education (CHE) audit, encouraged a compliance mentality through a 'tick box' mentality, thereby encouraging compliance of minimum standards. Thus, quality assurance audits became a 'feared' phenomenon in all higher education institutions in South Africa. The complete lack of stewardship in addressing the culture of quality and its' implications for continuous improvement has led to inefficiencies in the entire higher education landscape. In this paper the 'fuzzy' and perhaps 'slippery' nature of quality is addressed through a critical analysis of the concepts of development, enhancement and assurance in relation to the quality of teaching and learning in higher education through a case study methodology using qualitative analysis in an open distance learning institution (ODL). The key argument is that although quality is important for improvement, practices at the institution are not changing in the way they should because of a quality culture that is determined by the Department of Higher Education and Training. Hence the research question is to determine the status of quality with a view of recommending total quality management as a strategy that would enhance the practice of quality in the organization. Therefore, this paper explores the current quality practices with the intent to improve the delivery of teaching and learning in an ODL environment.

Keywords: Quality practices, open distance learning, total quality management, quality management, re-engineering.

\section{INTRODUCTION}

Brennan and Shah (2000) affirm a basic framework for the management of quality assurance in higher education. The current application of quality emanates from the HEQC model that consists of 19 criteria adopted for the purposes of accountability in South Africa. Due to commendations and recommendations made by the first CHE audit, institutions placed more emphasis on quality assurance centers (Boughey and McKenna, 2015). The implementation of $Q A$ centers necessitated higher education institutions to reengineer themselves through the development of new vision statements, increased alliances both nationally and internationally, and improved quality enhancement (Boughey, 2007). 
Quality assurance is directly linked to academic development in terms of improving the teaching and learning agenda of institutions. It is also instrumental in enabling the development of criteria in order to stipulate awards for exceptional performance in teaching and learning (Boughey, 2007). The HEQC applies quality assurance as a measurement tool for public accountability, improved teaching and learning, consolidated administrative processes, informed student choices, and a means of continuous improvement in higher education processes. This led to quality becoming a dominant discourse at institutional level (Boughey, 2007).

There are numerous reasons for quality becoming strategically important in all spheres of higher education undertakings. Some of the important reasons are indicated below:

$>$ Intensifying global competition. The customers and consumers of the $21^{\text {st }}$ century are in search for competitive quality and added value at a low cost.

$>$ Growing expectations. Customers and consumers demand value for money in all facets of their encounters with the service provider. Higher education students expect high quality education at minimal cost.

$>$ Impact of \#feesmustfall. The student uprising can be seen as both detrimental and important. It impacts the entire higher education system by its very nature through the destruction of property as an immediate effect. The financial status of many institutions is in jeopardy. This means that higher education requires considerable re-engineering in the provision of educational services (Ramdass, 2016).

\section{LITERATURE REVIEW}

\section{Defining Quality in Higher Education}

Numerous authors have defined quality in higher education. Harvey and Green (1993) provide five conceptual definitions of quality, that is, quality as: exceptional, perfection (or consistency), fitness for purpose, value for money and transformative. Luckett (2006:14) defines quality assurance as: "systematic internal and external management procedures and mechanisms by which HEIs assure stakeholders of the quality of its systems, processes, products and outcomes and its ability to manage the maintenance and enhancement of quality". This definition subsumes quality assessment, management and enhancement. Luckett defines quality enhancement as: "commitment to improvement and development, usually intrinsically motivated in response to personal or professional drivers (Luckett 2006:14)". Harman (2000) defines quality as "systematic management and assessment procedures adopted by higher education institutions and systems in order to monitor performance against objectives, and to ensure achievement of quality outputs and quality improvements" (Harman, 2000:1). Of all the divergent definitions of quality, the ones that align to the HEQC are "fitness for purpose" and "value for money" with student "transformation being a key component" (Cheng, 2011).

The Council on Higher Education (CHE) uses the term "quality assessment," as the evaluation of the level of institutional quality (Brennan and Shah, 2000). The methodology in this assessment encompasses four aspects, namely:

$>$ The CHE as the co-ordinating body

$>$ External evaluation by academic peers

$>$ Institutional self-evaluation

$>$ Published reports

The CHE oversees the quality of education in South Africa. There is limited academic freedom and institutional autonomy where institutions are required to comply with quality practices from the CHE. The experience of the "audit and compliance" culture is a limiting factor in the quest for continuous improvement. This is because the audit process leads to demotivation of university staff. This contradicts to the quality philosophy of Deming, Juran and Crosby where empowerment and participation are important components of quality assurance (Goetsch and Davis, 2014). 
Quality Management in Higher Education

The global transformation in higher education over the past two decades has led to South Africa implementing national policies in order to measure the performance of institutions (Boughey, 2007; Cheng, 2011). The first being the Higher education Act of 1997 that set the platform for QA and is summarised as: "to provide for quality assurance and quality promotion in higher education". This led to the creation of the CHE, SAQA and the HEQC.

The CHE is responsible for:

$>$ Guide the DHET in terms of higher education policy directives

$>$ The development and implementation of a QA system that manages all quality related matters.

$>$ Development, monitoring and measuring of the higher education system (CHE, 2013)

The HEQC's definition of quality focuses on three specific areas: namely,

$>$ Fitness for purpose, an evaluation of how well an organization fulfills its stated mission

$>$ Value for money, is judged on the basis of efficiency and effectiveness in the provision of teaching and learning

$>$ Transformation, the development of the learner through teaching and learning that meets the needs for social and economic growth. Transformation in HE is underpinned by quality assurance mechanisms for the need of quality education and a fair chance of academic success (Scott et al, 2007)

Harvey and Knight (1996) question the concept of "fitness for purpose" by questioning the measurement of "fitness" and "the purpose of higher education." They further mention that purpose in the private sector is defined by customer requirements and stipulations. Harvey and Knight (1996) reject these assertions on the basis that students are not customers who can define their requirements. Instead they mention that students may be seen as participants in the teaching and learning process.

The concept of "value for money" is a market related concept that is used for accountability, improved efficiency and effectiveness as well as competitiveness (Harvey and Knight, 1996). Judgements in relation to efficiency and effectiveness include the response of the labor market as well as cost implications. Harvey and Knight (1996) posit 'quality as transformation' which implies a change of form where education is seen as a transformative process and the student a participant in the process. From and engineering perspective transformation is seen as a change process in the composition of society through value- adding variables (Belawati and Zuhairi, 2007).

The HEQC's definition is comprehensive which co-insides with Barnett's argument that quality is defined in context and what the definer wants it to be. Therefore the notion of quality in higher education is regularly challenged and should be seen as a philosophical issue (Barnett, 2000). Harvey and Green (1996) indicate that quality assurance is a systematic approach that enables 'doing things right the first time every time' while ensuring that systems are in place and effectively managed.

\section{RESEARCH METHODOLOGY}

This paper adopted a qualitative methodology, through a case study, to determine quality practices currently applied across in the institution and to recommend and improve service to students. With the application of case study methodology complex phenomena are studied in particular contexts with theory development, situation analysis interventions. It enables the funneling of an expansive field into manageable research themes. The research question is answered to a greater or lesser degree through the amplification of the topic into scientific theories and models. The study was conducted through invitation of $\mathbf{6 0}$ academics staff chosen at random in the university. The research question that was asked was "what is your perception of the current quality practices in 
your work environment." In addition three focus group interviews were held with a mixture of staff in the university. Literature reviews provided theoretical underpinning of the research. Data was attained through these discussions with various departments at all hierarchical levels in the various colleges regarding their perceptions of quality in the institution. The data obtained was analyzed through content analysis and summarized into themes that follow.

A qualitative methodology through a case study was applied for the purpose of comprehensiveness to provide for unexpected developments and clarify idiosyncratic circumstances. Further, the literature review consolidated the theoretical underpinning of this study which assured the reliability and validity of the measuring instruments. The description of the research design and methods presents the rationale for decisions in data collection and deconstruction.

\section{FINDINGS}

The following themes emanated through the discussions and focus group interviews to determine the current practices of quality in the institution. It is important to note that many people did not understand the importance and impact of quality from external stakeholders.

Theme 1: Policing Practices

The information from both the focus group interviews and discussions regarding the status of quality are summarized in this section. Discussions highlighted the "policing" practices that stem from the CHE and the interrogating nature practiced through audits that leave institutions uneasy. It was mentioned that it is impossible for a quality assurance department to successfully attain the desired impact that quality deserves due to the silo mentality at the institution. The South African Constitution enshrines academic freedom and institutional autonomy as core values. Threats to academic freedom were debated at great length and concluded that the existence of bureaucracies of both institutions and government, the practice of managerialism, commercialization of higher education, limitation of the voice of the academic and the lack of transformation are constraints in the organisation. The audit report of the CHE creates an environment of compliance and limits the ability of continuous improvement in higher education (Luescher, 2008).

Theme 2: Understanding the Importance of Quality

The academic and support staff are the implementers of quality and many do not understand the importance of quality. One of the major reasons for this is the lack of management commitment in driving quality throughout the institution. The audit culture is difficult to change even though the CHE has embarked on changing its strategy through the implementation of the quality enhancement project (QEP). Since this has been implemented in the last year, cultural change in embracing quality as everyone's responsibility will indicate the success of the QEP.

Theme 3: Policies

People are forced to comply with institutional and governmental policies and this is not taken well by staff. Staff complained about the integrated performance management system (IPMS) that they believed was not fair due to discriminatory practices. The IPMS measures staff performance in teaching and learning, research, community engagement and academic citizenship. This is where academics are accountable for what they do.

\section{Theme 4: Funding}

It was mentioned that one of the debilitating issues related to a change in the culture of quality is that of funding. In order to implement a quality system there needs to be a change management strategy that would develop a project plan as to achieving success in quality in the institution. However, with limited resources, higher education institutions throughout South Africa are challenged with financial constraints. 
Theme 5: Workload

Many academics and support staff mentioned that their workloads are increasing from time to time without additional remuneration. This leaves many staff disgruntled and demotivated. The concept of quality is imperative in terms of continuous reflection for improvement of all facets of higher education. It is contradictory in terms of the culture of quality as it is all "talk" reflected in a lack of peoples' engagement with quality in their daily tasks.

\section{Theme 6: Trust}

Another major limiting factor in terms of quality assurance and enhancement is that of a lack of trust (Kruger and Ramdass, 2011; Harvey and Williams, 2010). Due to the diversity of cultures and racism experienced in higher education, the development of trust is inhibited and consequently debilitating to QA. In viewing the lack of trust as an inhibiting factor, leadership of higher education institutions require engagement with the issue. Trust and honesty are supposedly embedded in the institutional community through discussions from the Vice Chancellor's office via weekly ethics dialogue. The impact on individuals is limited. The "quality" of relationships in HEI is determined by the level of trust among diverse people. One of the important facets of quality is teamwork. If people do not trust each other there is limited teamwork. Although people "seem' to be co-operative, it is difficult to fathom what is in their mind and this ultimately limits the progress of quality in higher education (Ramdass, 2016).

Theme 7: ICT

Staff was "up in arms" regarding the performance of the information and communication system. They mentioned that "we are an ODL university but our systems fail us." ICT systems are in the process of being addressed.

\section{RESULTS AND DISCUSSION}

\section{Quality Philosophy at the Institution}

On critical examination of the progress of quality assurance practices, limited gains were made in terms of changing the quality culture of the institution. A lot more can be done in terms of people engagement and understanding the importance of quality. Quality management requires management commitment and leadership for successful implementation (Houston and Paewai, 2013). Boughey and McKenna (2015) argue that institutional audits were predominantly focused in the realms of structure and agency, and did not challenge the notions of students, teaching and the curriculum.

The quality philosophy is well grounded in the institutions policies as well as in the mission, vision and values statement. These are introduced to new personnel and readily available on the university's intranet. However the challenge is whether staff engages and reflect on them (Daft, 2006). Commitment and guidance from management is imperative for the implementation of quality assurance that requires regular follow-up (Daft 2006).

\section{The Systems View of Quality}

The ideology of the systems view of quality entails international quality practices through benchmarking, national quality practices driven by the $\mathrm{CHE}$ and institutional quality practices including governing bodies. These practices are problematic at the institution due to the silo mentality that is embraced (Houston and Paewai, 2013). In addition the systems view evaluates quality in terms of the interactions of variables that are considered to be the input, the process and the output that enables interaction among departments. It is important to note that the student may be considered part of the input. The educational process from $1^{\text {st }}$ year to completion may be considered as the transformation process and the output is the successful student. Therefore the quality of the input will determine the quality of the output. The quality of the interaction of these variables would ultimately determine the quality of the learning experience. It is 
relatively easy to judge the tangible variables that interact with one another in comparison to the less tangible aspects such as the learning process. Quality aspects in ODL are fourfold and include:

$>$ Quality of products such as the development of study materials

$>$ Quality of processes that include the teaching and learning processes, communication with regional centers and so forth

$>$ Quality of production include delivery systems, print production, multimedia production, scheduling, podcasts, vodcasts, tele-conferences

> Quality of philosophy encompasses the vision, mission, values, policies, governance, institutional culture and public image.

The evaluation of quality of all the above variables is done through engagements with staff, students, peers, tutors, e-tutors through the Directorate of Strategic Planning and Quality Assurance (DSPQA) and the university research department. On completion of an assessment, a report is formulated and presented to the head of the department. From time to time, peers are selected to review study materials and tutorials through a checklist. This is collated by the Directorate of Strategic Planning and Quality Assurance (DSPQA). Improvement plans are compiled and monitored during departmental discussions and driven by the head of department (HOD).

\section{Project Mvusuludzo}

The current uproar by students has impacted HEI's in all aspects of teaching and learning and has placed major financial strain on institutions which ultimately influences the quality practices in HE. For this reason, the Vice Chancellor has instituted project "Mvusuludzo" which means renewal or redesign which is aimed at the evaluation of the entire teaching and learning system aided at improving service delivery to staff and students. This will require the redefinition of systems, policies, procedures, processes, structures that would enhance institutional effectiveness. The scientific approach of total quality management approach (where all stakeholders engage with quality) would enable a holistic approach that would look at the operation of ODL as an integrated whole. This would enable quality improvement to become part of the culture of the institution through the engagement of all stakeholders.

One of the major contributors to quality improvement and enhancement in an institution is the "voice of the customer" that would contribute directly in measuring student experiences in the educational process. Student engagement would encourage collaboration and is likely to improve the status of learning in higher education (Coates, 2005).

The Practice of Quality in an ODL Context

ODL has evolved at the institution over the past 140 years. Due to the intensification in student numbers, the university has appointed tutors and e-tutors, firstly to improve pass rates and secondly to decrease the burden of workload to lecturers. This promulgates interactive discussions among students and tutors, where the quality of discussions is scrutinized by the lecturer and the coordinator to determine their effectiveness and value-add. Therefore, it has become fundamental that the quality of these dialogues contribute to improved student experiences in open distance learning.

In an ODL context, the principal mode of service delivery used in teaching and learning is technology. Therefore, the communication platform needs to be robust, reliable and durable in order for effective teaching and learning to occur. Elements of quality in an ODL context include instructional design, content development, media production, delivery, student support, assessments, regular communication, human-software interface and the like. It is of critical importance that all correspondence is viewed through the lens of quality and professionalism as these are under constant scrutiny through the eyes of the public (Bates, 2000). 
The Compliance Mentality

The assurance of quality at Unisa is predominantly compliance based and requires inspection and control procedures. The compliance methodology is in direct contrast to the current concepts of academic freedom and social justice that underpin current practices. In addition, the compliance mentality is to the detriment of institutions and its staff. Firstly, it creates uneasiness in terms of the "audit" based practice applied where the "CHE bullies the entire process leaving people unhappy" (Ramdass, 2016). Secondly the CHE fails to engage and promote discussions that induce the enhancement of quality. Barnett in Doherty (2003) postulates that institutional audits, program accreditation and national review process are viewed as administrative burdens that deal with matters in a programmed way rather than cross-examining cause and effect (Luckett, 2006). There is little debate across HEI's as to what quality is and how to assure it. However, the CHE drove quality as fitness for and of purpose from 2004 to 2012 and has now taken the route of the Quality Enhancement Project which focusses primarily on teaching and learning.

One of the important priorities among stakeholders and the CHE is the assurance of quality in an open distance learning institution such as Unisa. Exploratory evidence in terms of student participation rates in surveys provides a $3 \%$ response rate to the quality of their experiences. It is extremely problematic to develop concrete recommendations from these surveys. Unisa adopted and contextualized the criteria of the CHE as a basis for its quality assurance mandate.

Open distance learning environments are under constant scrutiny as students pass rates are the lowest of all HEI's in the country and they are compared to those of face to face institutions. Students request frequent attention and flexibility, and the student population is diverse with wide ranging requirements. This places tremendous pressure on all systems and processes in the institution (Daniel,1999).

From a structural perspective quality assurance is a standing item on the agendas of all colleges at Unisa, both in academic departments and support functions such as the College Teaching and Learning Quality Assurance Committee (CTLQAC). The objective of this is the promotion of quality in the college and departments. However, the reality is that people are "silent" when quality appears on the agenda. The structures provide the framework for quality practices; however, culture and agency are problematic.

The ultimate test of measuring quality is the ability of students to secure jobs. As a result of globalization, massification and the economic crisis, job opportunities have reduced and graduates are forced to seek employment outside their fields of study. When students find employment within their fields, they are required to go through a structured training program. This does not portray the 'quality' of graduates emerging from the transformation process of higher education (Storen and Aamodt, 2010).

\section{Continuous Self-Examination}

The implementation of TQM requires drastic change in mindset in order to impact work culture. Everybody needs to "walk the talk" by firstly addressing diversity issues, showing respect, appreciation and applying the quality principles in everyday communication. These innovations and changes require management monitoring so that gains can be documented, and the culture of transformation towards TQM be supported. Therefore the leadership of the institution requires perseverance, commitment and endurance to ensure that there is a positive impact throughout the institution. Academic development (AD) and Quality Assurance (QA) co-exist alongside each other where quality related work is conceptualized, developed and managed in order to harness the potential of available resources through agency (Boughey, 2007).

Quality Enhancement Project

One of the fundamental barriers to the development of QEP was that a few selected people were tasked to engage and provide their input on the status of quality in the 
institution. Their views only provide quality assurance as if "all is well in the institution." This portrays an image of excellence when the reality is different. The CHE calls this report QEP, and does not engage institutions in terms of building a robust foundation where quality would thrive. The institutional report does not portray the true reflection on the status of quality management. Enhancement is about improving the learning experience, which is supposed to be the core function of the university. The report addresses four issues:

\section{Enhancing Academics as Teachers}

The institution is in a unique position in that it draws from a pool of academics and aspirant academics who may have roots in residential university contexts but who may not necessarily have a distance education background. Such staff members would be recruited for their disciplinary knowledge and thus need institutional support in the effective use of technology in online and blended learning environments. A distance education environment requires specific competencies for developing study materials, conducting assessment and facilitating learning. These are key issues that should form the core of professional development of new teaching staff (QEP, 2015).

Academics are also required to engage with the scholarship of teaching and learning and thus the integration of teaching and learning, research and community engagement forms part of their continuous professional development. Engaged academics are sustained by institutional strategies that continuously motivate and recognize them in the form of rewards dedicated to teaching and learning (QEP, 2015).

\section{Enhancing Course and Program Enrolment Management}

Traditionally, Unisa had a practice of admitting all students who met the minimum admission requirements for any of its qualifications. This resulted in exponential growth that impacted negatively on all administrative processes and on teaching and learning. The University now embraces the notion of rigorous selection and placement of students in appropriate qualifications as a mechanism of adhering to the ministerial targets whilst ensuring it maintains its social mandate of increasing access to higher education (QEP, 2015).

The importance of stable and reliable ICT is central in the operation of the institution that needs to select and register students away from campus. However, ICT cannot be used exclusively given the socio-economic status and geographical distribution of our students where ICT infrastructure is not well developed (QEP, 2015).

In order for the institution to ensure it registers students in accordance with the targets contained in its enrolment plan, it is critical that it knows before the end of the registration period which students will take up the places offered to them. Failure to enforce such an arrangement, as contested by the student body, will at best result in an inability to reach the ministerial targets.

Enhancing Student Support and Development

The senate approved Framework for Student Support highlights the following areas of student support and development as key, both at entry level and during the teaching and learning phase.

Entry-level factors:

$>$ Confidence of students and motivation

$>$ Support of entering under-prepared students

> Preparation of students to study independently in an ODeL institution

$>$ Developing a sense of belonging to the institution 
Teaching and learning factors:

$>$ Orientation to each learning program

$>$ Access to an enabling environment (study materials, library, ICTs, regional offices)

$>$ Student engagement (active learning, interaction with study material, peers and instructors)

Enhancing the Learning Environment

As an Open Distance Learning (ODL) institution, the institution is acutely aware of its responsibility to minimize the transactional distance by inter alia making provision for teaching and learning spaces located in the regional centers scattered across the various South African provinces, a well-resourced, state of the art library (including those at the various Unisa learning centers), robust ICT systems and access to technology (QEP, 2015).

\section{RECOMMENDATIONS AND CONCLUSION}

In order to address the challenges mentioned above, it would be a viable proposition to consider the implementation of total quality management as a strategy to improve the current situation for the following reasons:

$>$ TQM was developed by harnessing related concepts into a collective strategy

$>$ It will address a culture change where everybody is engaged with understanding what quality means and the importance of quality

$>$ It would address the silo mentality where there would be teamwork among departments

$>$ It would create an environment where there is trust and honesty

$>$ It creates a platform for continuous process improvement.

$>$ It would empower all staff to take ownership and accountability in decision making

$>$ It is scientific in nature (Goetsch and Davis, 2014).

The implementation of TQM principles in ODL is a prodigious task. One of the major reasons for this is that "academics believe that they know everything" and tend to resist change. This endeavor requires patience, effort, socialization, training, workshops, continuous engagement and above all, management commitment at all levels. This is where Academic Development and the Quality Department can play a major role in terms of strategically planning the orientation of quality to all staff. Exploratory evidence indicates that people may talk about quality, but do not know what it means. Through continuous discussions and engagement, the mindset of staff at all levels would change to inculcate TQM principles into their everyday activities.

The TQM philosophy has proved results in both product and service related organizations. The application of this methodology enables structural, cultural and agential change that would enable continuous improvement which promotes enhancement. It is an active means of engagement which enables the formulation of cross-functional teams, reengineering of processes, active suggestion schemes, improvement and enhancement teams and quality becoming a culture of continuous reflection, change and development. There are several critical factors that enable the functioning of TQM. They are as follows:

$>$ Shared Vision. Mission, vision and values of the organization is practiced by all employees.

$>$ Integrity and honesty. Acknowledge that the organization is facing challenges and work on a rectification plan through engagement.

$>$ Perseverance. Changing the culture of people to embrace quality takes time, patience and research.

$>$ Commitment. Commitment by all employees to embrace the ideology of continuous quality improvement through active engagement.

> Long-Term Thinking. Use the experiences of the past to mould the future. 
$>$ People Management. Use the participative management style to embrace people as the most important asset.

> Knowledge exploitation. Use the talents within the organization in the resolution of problems (Kruger and Ramdass, 2011).

Throughout, institutional senior leadership is been required to demonstrate commitment through actively setting examples for all employees - this means from the sweeper to Vice Principals. This needs the provision of training and learning engagements, as well as supervision and guidance where required. The objective is self-reflection and reflexivity where the staff challenges all practices in order to affect improvement in all aspects of teaching and learning particularly the critical service staff on whom the academics and students are critically reliant, with the ramifications flowing from this into the more arcane divisions like finance and purchasing, arranging travel for academics to different teaching venues, and so forth (Webb, 2016).

External demands for quality assurance mechanisms will continue to influence the quality of higher education provision in South Africa into the distant future (Harvey and Williams, 2010). The ideology of performance and accountability that postmodernism created has stripped the traditional institutional autonomy and academic freedom previously enjoyed (Harker, 1995). A clear understanding of improvement and accountability as distinct concepts are required at national and institutional levels to which I agree as there is much more focus in separating these concepts (Middlehurst and Woodhouse, 1995). Accountability deals with the 'who and how' in terms of a consistent and transparent flow of information to stakeholders (Housten and Paewai, 2013). Thune (1996) argued that the two concepts of quality improvement and accountability may be combined as a balanced strategy. External quality assurance is important to drive internal quality strategies which enable dialogue and the development of an internal quality culture. However, to change external quality culture is a daunting task (Dano and Stensaker, 2007).

As an academic the belief is that collaboration, teamwork and perseverance are fundamental to ignite change in this huge university. Through the engagement of colleagues in the department and the teaching and learning committee to engage with quality on all aspects of teaching and learning that would change the current thinking. A "step at a time" would encourage change in the way the institution operates. Institutional and governmental pressure to enhance teaching and learning has led to the implementation of awards recognizing good teaching practice. What constitutes 'good' teaching may be subjective and politically motivated (Cheng, 2011).

The fundamental requirement for the implementation of $Q A$ is management commitment towards the development of a culture of quality (Harvey and Williams, 2010). In order to achieve this, senior leadership requires the understanding of the impact of quality in institutions so that QA can move from a compliance mode to one of continuous improvement. The mandate for $Q A$ as espoused by the CHE and higher education institutions require transformation into enhancement. The CHE requires an understanding of enhancement and need to develop a framework that would enable this process. When there is culture change in the $\mathrm{CHE}$, institutions would be able to change as well. Most often consultants are contracted by management to implement quality and evaluate the institution. The institutions are provided with a classy report which is often shelved. The current practice requires a change in mindset from the CHE and the institution. It is important to note that change cannot be successful in a hostile environment where managers separate themselves from the workforce. The incorporation of teamwork, employee empowerment, mutually supportive partnership increases the likelihood of efficiency and effectiveness.

TQM requires time for change. The mentality of short term gains as espoused by management is unlikely. Higher education institutions are dealing with an empowered workforce, so change will be slow. It is difficult to overcome the past where employees 
that have worked for a long period of time and experienced numerous management fads in the organization. The promotion of TQM would require patience and endurance. Ongoing commitment and funding, together with an open mind is imperative in the implementation of TQM. The methodology has been proven in numerous organizations worldwide, and has therefore been chosen as a strategy that is likely to bring about change in a constructive manner at all levels in the organization.

\section{BIODATA and CONTACT ADDRESSES Of AUTHORS}

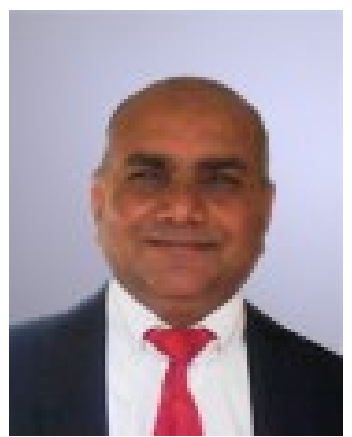

Dr. Kemlall RAMDASS is a senior lecturer in the Department of Mechanical and Industrial Engineering at the University of South Africa in Pretoria. He gained his Ph.D in Engineering Management at the University of Johannesburg in 2009. His academic interest lies in the re-engineering of processes using Industrial Engineering methodology for continuous improvement. His interests include quality in education and industry, open distance learning, operations management and service quality. He has over 43 published articles in conferences and journals and has also been the co-author of a book called Operations management by Oxford University Press.

Kemlall RAMDASS

Department of Mechanical and Industrial Engineering,

College of Science, Engineering and Technology

Private Bag X6, Florida, 1710, Johannesburg, South Africa

Phone: +27114712117

E-mail: ramdakr@unisa.ac.za

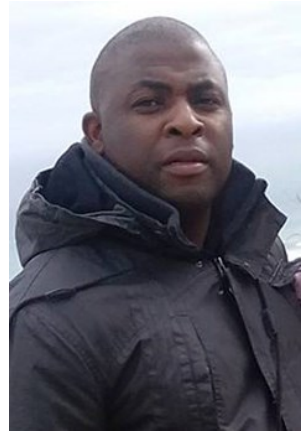

Dr. Fulufhelo NEMAVHOLA is a Senior Lecturer at the University of South Africa, Department of Mechanical and Industrial Engineering. He graduated with a Bachelor of Science in Mechanical Engineering and a Master of Since in Engineering from the University of the Witwatersrand, Johannesburg, South Africa. He has completed his PhD in Computational Biomechanics from the University of Cape Town, South Africa. His research is mainly in the area of soft tissue mechanics but has special interest in engineering education through open distance learning. Fulufhelo is a registered professional Engineer with the Engineering Council of South Africa. Furthermore, he is also registered as a Chartered Engineer with the Engineering Council of the United Kingdom.

Fulufhelo NEMAVHOLA

Department of Mechanical and Industrial Engineering

College of Science, Engineering and Technology

Address: Private Bag X6, Florida, 1710, Johannesburg, South Africa

Phone: +2711 4712765

E-mail: masitfj@unisa.ac.za

\section{REFERENCES}

Bradley, G. (2001). Towards a pragmatic scholarship of academic development. Quality Assurance in Education, 9(3), 162-170.

Brew, A., \& Peseta, T. (2008). The precarious existence of the academic development unit.

Boughey (2013) 'The significance of structure, culture and agency in supporting and developing student learning at South African universities' in Dhunpath \& Vithal (eds.) Alternative access to higher education. 
Boughey, C., \& McKenna, S. (2015). Analysing an audit cycle: a critical realist account. Studies in Higher Education, 1-13.

Boughey, C. (2007). Marrying Equity and Efficiency: The Need for Third Generation Academic Development. Perspectives in Education, 25(3), 27-38.

Belawati, T., \& Zuhairi, A. (2007). The practice of a quality assurance system in open and distance learning: A case study at Universitas Terbuka Indonesia (The Indonesia Open University). The International Review of Research in Open and Distributed Learning, 8(1).

Bates, A. W. (2000). Managing technological change: Strategies for college and university leaders. San Francisco: Jossey-Bass.

Brennan, J., \& Shah, T. (Eds.). (2000). Managing quality in higher education. Milton Keynes: OECD, SRHE \& Open University Press.

Coates, H. (2005). The value of student engagement for higher education quality assurance. Quality in Higher Education, 11(1), 25-36.

Crosby, P. B. (1980). Quality is free: The art of making quality certain. Signet.

Daft, R. L. (2006). Organizational Theory and Design, 9th Edition. Mason, OH.: Thomson Southwestern.

Daniel, J. (1999). Open learning and/ or distance education: which one for what purpose? In K. Harry (Ed). Higher education through open and distance learning (p. 292298). London: Routledge and Commonwealth of Learning.

Doherty, G. (Ed.). (2003). Developing quality systems in education. Routledge.

Deming, W. E. (1982). Quality, productivity, and competitive position. Massachusetts Institute of Technology Center for Advanced En.

Garrison, D. R. (1993). Quality and access in distance education: Theoretical considerations. In D. Keegan (Ed.) Theoretical principles of distance education (pp. 9-21). New York: Routledge.

Goetsch, D. L., \& Davis, S. B. (2014). Quality management for organizational excellence. pearson.

Garvin, D. A. (1984). Product quality: An important strategic weapon. Business horizons, 27(3), 40-43.

Gosling, D., \& D'Andrea, V. (2001). Quality development: a new concept for higher education. Quality in Higher Education, $7(1), 7-17$.

D'Andrea, V., \& Gosling, D. (2005). Improving Teaching And Learning In Higher Education: A Whole Institution Approach: McGraw-Hill Education (UK).

Harman, G. (2000). Quality assurance in higher education. Bangkok: Ministry of University Affairs \& UNESCO PROAP.

Harvey, L., \& Green, D. (1993). Defining quality. Assessment \& evaluation in higher education, 18(1), 9-34.

Hopkin, A. G., \& Lee, M. B. (2001). Towards improving quality in 'dependent' institutions in a developing context. Quality in Higher Education, $7(3), 217-231$.

Luckett, K. M. (2006). The quality assurance of teaching and learning in higher education in South Africa: an analysis of national policy development and stakeholder response (Doctoral dissertation, Stellenbosch: University of Stellenbosch).

Moore, M. G. (1993). Theory of transactional distance. In D. Keegan (Ed.) Theoretical principles of distance education (pp. 22-38). New York: Routledge. 
Quinn, L., \& Vorster, J. A. (2014). Isn't it time to start thinking about 'developing'academic developers in a more systematic way? International Journal for Academic Development, 19(3), 255-258.

QEP report. (2015). Unisa. Retrieved from http://www.unisa.ac.za

Juran, J. M. (1988). Juran on planning for quality. New York: Free Press.

South Africa. (1997). Higher Education Act, No 101 of 1997.

Scott, I., Yeld, N., \& Hendry, J. (Eds.). (2007). Higher education monitor: A case for improving teaching and learning in South African higher education. Pretoria: Council on Higher Education.

Scardamalia, M., \& Bereiter, C. (2006). Knowledge building. The Cambridge. Retrieved from http://www.che.ac.za/about/overview 